\title{
INDISCIPLINA NO ENSINO SUPERIOR: PERSPECTIVAS DOCENTES E DISCENTES
}

\author{
INDISCIPLINA IN HIGHER EDUCATION: TEACHING AND TEACHING PERSPECTIVES \\ INDISCIPLINA EN LA ENSEÑANZA SUPERIOR: PERSPECTIVAS DOCENTES Y DISCENTES
}

\author{
ROSA, Aparecida Silvério ${ }^{1}$ \\ MÁRQUES, Fernanda Telles²
}

\section{RESUMO}

O artigo reflete sobre questões disciplinares no ensino superior. Trata-se de uma investigação em abordagem qualiquantitativa, bibliográfico-documental e de campo. Os resultados identificaram como condutas indisciplinadas os mesmos comportamentos, alunos ingressantes atribuem menor gravidade a cada um dos eventos em comparação aos concluintes e aos professores. As concepções dos participantes remetem às apresentadas em Aquino (1996), que relaciona a indisciplina aos comportamentos que se contrapõem às normas preestabelecidas para o bom andamento das atividades escolares. Conclui-se que, indisciplina diz respeito, muito mais, à falta de atenção e concentração na aula e/ou na atividade proposta.

Palavras-chave: Processos educacionais. Indisciplina. Ensino Superior

\section{ABSTRACT}

The article reflects on disciplinary issues in higher education. This is an investigation in a qualitative, bibliographic-documentary and field approach. The results identified the same behaviors as unruly behaviors, incoming students attribute less seriousness to each of the events compared to the students and the teachers. The conceptions of the participants refer to those presented in Aquino (1996), which relates the indiscipline to the behaviors that contradict the pre-established norms for the good progress of school activities. It is concluded that, indiscipline refers much more to the lack of attention and concentration in the class and / or proposed activity.

Keywords: Educational processes. Indiscipline. Higher education.

\section{RESUMEN}

El artículo reflexiona sobre cuestiones disciplinarias en la enseñanza superior. Se trata de una investigación en abordaje cualitativo, bibliográfico-documental y de campo. Los resultados identificaron como conductas indisciplinadas los mismos comportamientos, alumnos ingresantes atribuyen menor gravedad a cada uno de los eventos en comparación a los concluyentes y los profesores. Las concepciones de los participantes remiten a las presentadas en Aquino (1996), que relaciona la indisciplina a los comportamientos que se contrapone a las normas preestablecidas para el buen andamiento de las actividades escolares. Se concluye que, indisciplina se refiere, mucho más, a la falta de atención y concentración en la clase y / o en la actividad propuesta.

Palabras clave: Procesos educativos. Indisciplina. Enseñanza superior

\footnotetext{
1 Centro Universitário de Patos de Minas - UNIPAM - Pato de Minas - Minas Gerais - Brasil

2 Universidade de Uberaba - UNIUBE - Uberaba - Minas Gerais - Brasil
} 


\section{INTRODUÇÃO}

A questão disciplinar sempre esteve presente em discursos sobre o cotidiano e as condições de realização do trabalho docente. Fala-se cada vez mais em indisciplina, contudo, ainda que também se manifeste no ensino superior e que não raro se torne pauta de reuniões pedagógicas, no Brasil, pouco se vê produção acadêmica a respeito. As pesquisas que se voltam à temática ainda se ocupam majoritariamente da educação básica.

Para refletir sobre a questão, partimos de autores que têm em comum algum diálogo com a leitura foucaultiana dos dispositivos disciplinares. Assim, além de Foucault (1999, 2003, 2004a, 2004b) em quem encontraremos uma discussão sobre a disciplina enquanto técnica de governamento, com Portocarreiro (2004) refletimos sobre os processos de normalização ocorridos na instituição educacional, e em Aquino (1996, 2003, 2009, 2016) vemos que, os conflitos disciplinares que se dão no ambiente universitário guardam íntimas relações com questões sociais do mundo contemporâneo, que vão desde peculiaridades das formas de sociabilidade juvenil, até a necessária revisão da noção de disciplina escolar.

O objetivo da pesquisa é analisar comparativamente os entendimentos de professores e estudantes universitários acerca da tensão disciplina/indisciplina no ensino superior. Como os poucos trabalhos sobre o tema a que tivemos acesso referiam-se a ambientes universitários das áreas de Ciências Humanas, Sociais Aplicadas ou Licenciaturas, buscamos verificar como a questão seria vista e vivenciada pelos partícipes de um ambiente acadêmico que não tivesse as temáticas da disciplina e das relações de poder como parte de seu conteúdo curricular - decorrendo disso a escolha pelo curso de Medicina Veterinária.

Para alcançar o objetivo proposto optamos por uma abordagem qualiquantitativa, assim entendida a partir da perspectiva de Chizzotti (1998). Dessa forma, fizemos uso de um instrumento misto (com questões abertas e fechadas), que foi aplicado a um total de 158 sujeitos distribuídos entre alunos ingressantes, alunos concluintes e seus professores. As respostas foram sistematizadas em categorias temáticas e discutidas à luz do referencial teórico.

\section{DISCIPLINA ESCOLAR COMO FORMA DE GOVERNAMENTO}

Em seus estudos sobre a tensão disciplina/indisciplina, Aquino (2009) observa que as contribuições de Foucault são essenciais para a análise do disciplinamento, visto como prática que emergiu nas sociedades ocidentais ao final do século XVIII. O estudioso de Foucault registra que "as instituições disciplinares teriam se constituído em consoantes a procedimentos de controle bastante minuciosos" (AQUINO, 2009, p. 58), destacando-se, dentre eles, "racionalização do espaço, do tempo e dos corpos dos indivíduos sob sua tutela" (idem).

Para Foucault (1999, p.89) a disciplina é uma das ferramentas utilizadas na manutenção do poder, contudo, diferente de outras correntes teóricas que se voltam ao mesmo tema, o filósofo 
entende que "esse poder não diz respeito à dominação de uma classe superior sobre uma inferior, mas a um poder que circula entre a população, presente em todos os setores da sociedade".

Conhecendo o processo de escolarização das massas populares iniciado naquele período, o sistema escolar desenvolveu processos de organização disciplinar, baseados em normas, sanções e registros em regimentos escolares. Como explica Portocarreiro (2004, p. 172),

a disciplina organiza o espaço através de uma repartição dos indivíduos; controla a atividade através do controle do tempo; especifica o indivíduo generalizando-o através de uma vigilância hierárquica; organiza as diferenças através de uma sanção normalizadora e reproduz e produz saber através do exame.

O sucesso do que passa, então, a ser considerado como "boa educação" decorre do desenvolvimento de algo que Foucault (1999) chamou de dispositivos disciplinares: o olhar hierárquico em que a vigilância era favorecida pela organização; a separação e o distanciamento entre educador e educando; o domínio sobre os movimentos corporais e a produtividade do dominado numa relação de poder; e o exame, que permitia qualificar, classificar e punir, fazendo da escola "examinatória" o local onde "advém uma pedagogia que funciona como ciência" (idem, p.211).

Márques e Sousa (2016, p. 119) consideram que o estudo de Foucault é especialmente oportuno para a pesquisa em educação porque o autor nos leva a perceber que

este processo de disciplinarização transforma o ser em sujeito, resultado dos aparelhos disciplinares implantados na sociedade Ocidental, que atuam com firmeza no sentido de fazer com que a conduta do sujeito comungue com a moral hegemônica. E é assim que o poder disciplinar manifesta sua função normalizadora, adestrando um coletivo enquanto impõe seus mecanismos de maneira individualizada.

Os dispositivos usados no processo em questão se fazem presentes em toda a sociedade, incluída, portanto, a escola, forte usuária de recursos disciplinares. Pela perspectiva foucaultiana tais recursos objetivam docilizar os corpos, o que significa "esvaziá-los de sua potência política para elevar ao máximo sua potência produtiva" (MÁRQUES; SOUSA, 2016, p. 119).

$\mathrm{Na}$ escola os indivíduos são moldados, docilizados e controlados através do saber que a própria escola produz sobre eles. O pensamento de Foucault nos oferece, assim, um conceito interessante, pois ligado à disciplina escolar permite entendê-la enquanto uma forma de governamento. Trata-se do conceito de governamentabilidade, que, conforme exemplo apresentado por Veiga-Neto (2003, p. 5), pode ser compreendido como "a dobradiça que nos permite mostrar uma articulação entre a genealogia do Estado e a genealogia do sujeito moderno".

Embasados na teoria foucaultiana, Aquino e Ribeiro (2009, p.61) ressaltam, que "é pelos processos de governamentalização que se perfaz um duplo golpe: a regulamentação das condições de vida das populações e a disciplinarização da existência de seus componentes individuais". Explicam os autores que a sociedade disciplinar produziu a necessidade de unificar dois níveis paralelos e ao 
mesmo tempo complementares de gestão social da vida: "o anátomo-político, por meio do disciplinamento do corpo-máquina, e o biopolítico, por meio da regulamentação do corpo-espécie (previsões, estatísticas, medições globais)" (idem, p. 61). Assim, os processos de governamentalização constituiriam o ponto certo de articulação das tecnologias de si e das tecnologias de dominação sobre os outros, agindo de modo similar no que diz respeito à conduta de todos, em conjunto, e de cada um, em separado.

A ordem disciplinar justifica as condutas individuais, tornando-as úteis, por meio da união ao padrão normativo, na medida em que a gestão governamentalizadora controlaria as condições da existência por meio do cálculo incerto, regulamentando, assim, o início das variações das condutas da população em relação à norma.

Segundo Aquino e Ribeiro (2009) são processos de governamentalização pedagógico-escolar da atualidade educacional: ensinar aos alunos, discipliná-los e avaliá-los continuamente, para, assim, torná-los futuros homens. Na justaposição de repetição com circularidade estariam os principais contornos da governamentalidade escolar. Neste sentido, em contraposição à ideia de que o poder é $o$ mal, Foucault (2004) argumenta que o mal não está no poder, mas na ausência de uma reflexão crítica sobre o emprego de técnicas abusivas. A exemplo, cita o caso da pedagogia escolar, deixando claro que não vê mal "na prática de alguém que, em um dado jogo de verdade, sabendo mais do que um outro, Ihe diz o que é preciso fazer, ensina-Ihe, transmite-Ihe um saber, comunica-lhe técnicas" (idem, p. 285).

A questão do uso abusivo da autoridade de forma a resultar em exercício de dominação deveria, então, ser colocada não apenas em termos de regras de direito ou de técnicas racionais de gestão, mas também como uma prática de si e de liberdade (FOUCAULT, 2004). Tal prática, na concepção do filósofo, permitiria o desenvolvimento do cuidado-de-si, que é algo fundamental também para que o sujeito desenvolva a capacidade de cuidar do outro - e, portanto, para que esteja apto ao exercício de uma ética da liberdade. Ética esta que exige que não tome como referência apenas sua própria existência.

\section{A INDISCIPLINA PELA PERSPECTIVA DOS PARTICIPANTES DA PESQUISA}

Iniciamos a pesquisa de campo buscando conhecer quais comportamentos seriam entendidos, por aqueles que estão mais diretamente implicados no processo educacional: professores e alunos ou seja, o que seria por eles considerado como indisciplina. Na sequência, levantamos elementos favorecedores da compreensão, do quanto estes eventos implicariam, na percepção de cada grupo de sujeitos, em prejuízos ao processo educacional e/ou ao desempenho profissional.

Na pesquisa documental realizada a partir do Projeto Pedagógico do Curso (PPC) e do Estatuto da IES, constatamos que a perturbação da ordem, o desrespeito aos membros da comunidade escolar e a ocorrência de comportamentos prejudiciais ao bom andamento do processo 
educacional, são posturas sinalizadas como merecedoras de sanções disciplinares. Por meio delas, estaria se expressando o que é chamado de indisciplina.

Em uma das questões do instrumento apresentamos uma relação de situações antes observadas no ambiente universitário: trocar bilhetinhos ou mensagens durante a aula; conversar enquanto o professor está com a palavra; conversar enquanto um colega está com a palavra; interromper a fala do professor ou de um colega com questionamento ou colocação pertinente ao assunto; interromper a aula com ironia ou sarcasmo dirigido a quem está com a palavra (seja professor ou colega); permitir que o celular toque durante a aula; atender ao telefone celular durante a aula; navegar na internet durante a aula, sem que isso tenha sido solicitado ou autorizado pelo professor; utilizar fones de ouvido durante a aula; fazer perguntas ou observações que não têm relação com o assunto tratado em aula; não dar atenção/ignorar o professor enquanto este se dirige à turma; não atender à solicitação do professor quando este chama a atenção da turma ou reclama de indisciplina. Solicitamos aos participantes que assinalassem apenas as ocorrências por eles consideradas como indisciplina no ensino superior, e também reservamos um espaço para que fossem inseridas situações porventura não contempladas no instrumento ${ }^{3}$.

O grupo dos professores foi unânime em relação a quatro das 12 situações. Todos os docentes abordados consideraram que se trata de indisciplina: atender ao telefone celular durante a aula; conversar enquanto o professor está com a palavra; interromper a aula com ironia ou sarcasmo dirigido a quem está com a palavra (seja professor ou colega); e não atender à solicitação do professor quando este chama a atenção da turma ou reclama de indisciplina.

As situações em questão têm em comum o aparente enfrentamento da autoridade docente, mas em uma delas, em especial, fica mais ressaltado um elemento que tem sido muito discutido na literatura, a partir da noção de incivilidade, tratada por autores como Charlot (2002) e Debarbieux (1999) como uma forma de transgressão das normas realizadas com deliberada rudeza.

Neste sentido, cabe chamar a atenção para o fato de que, em obra posterior, elaborada em coautoria com Blaya, Debarbieux (2001) ponderou que, nas relações educacionais o que tem sido chamado de incivilidade não é algo a ser pensado, a partir da dicotomia barbárie, posto que, a existência de uma atmosfera hostil não depende de falta de educação ou de civilidade. Assim, reconhecendo o etnocentrismo sugerido pelo conceito, o autor observou que em se tratando de relações educacionais, o mais adequado seria fazer uso da noção de microviolência. Interromper a fala de alguém no ambiente da sala de aula, dirigindo-se à pessoa com ironia ou sarcasmo é um gesto de microviolência, pois, ao mesmo tempo em que se faz presente um aspecto intimidatório, este se manifesta travestido de humor e por isso, nem sempre é reconhecido como um ataque à pessoa a quem foi dirigido (MÁRQUES, 2015).

\footnotetext{
${ }^{3}$ Apenas um docente acrescentou que outra manifestação de indisciplina não prevista no instrumento seria o trânsito de aluno entrando e saindo da sala no decorrer da aula.
} 
Relacionada à conscientização dos objetivos da disciplina, Foucault (1999, p.195) diz que:

\footnotetext{
O poder disciplinar é com efeito um poder que, em vez de se apropriar e de retirar, tem como função maior 'adestrar'; ou sem dúvida adestrar para retirar e se apropriar ainda mais e melhor [...] A disciplina 'fabrica' indivíduos; ela é a técnica específica de um poder que toma os indivíduos ao mesmo tempo como objetos e como instrumentos de seu exercício.
}

Esta forma de desrespeito aos membros da comunidade escolar, assim caracterizado no Estatuto da IES, não é percebida como um inconveniente apenas para o corpo docente. Também para o grupo dos alunos a assertiva interromper a aula com ironia ou sarcasmo dirigido a quem está com a palavra (seja professor ou colega) esteve entre as mais identificadas como indisciplina $(94,2 \%$ dos concluintes e $95,7 \%$ dos ingressantes).

As respostas dos alunos indicam um entendimento muito similar ao de seus professores, no momento de classificar o que é e o que não é indisciplina. As quatro situações mais identificadas como indisciplina pelo grupo dos ingressantes foram exatamente as mesmas assim vistas por seus professores, alterando-se apenas os percentuais. Resultado parecido foi encontrado no grupo dos alunos concluintes, que, por uma pequena diferença, no lugar de atender ao telefone celular em aula, tiveram entre seus quatro principais resultados utilizar fones de ouvido durante a aula $(88,5 \%)$.

Outro dado que merece ser ressaltado é o apontamento de que, enquanto apenas um pequeno grupo dos professores compreendem que interromper a fala do professor ou de um colega com questionamento ou colocação pertinente ao assunto $(8,3 \%)$ e fazer perguntas ou observações que não têm relação com o assunto tratado em aula (25\%) se configure como indisciplina, para os estudantes, sobretudo os concluintes $(69,2 \%)$, estes são comportamentos indisciplinados, assim entendidos porque interferem na concentração dos demais alunos.

O dado é importante porque indica, em cada grupo, uma tendência tratar como indisciplina aquilo que é percebido como obstáculo para o alcance de seus objetivos. Próximos ao final do curso e já preocupados com sua inserção no mercado de trabalho, os alunos concluintes são o grupo menos tolerante em relação à participação de seus colegas, vista como algo que atrapalha a aula.

Para checar a hipótese de que muito dos conflitos em sala de aula decorreria do fato de professores e alunos terem entendimentos distintos não apenas sobre o que é ou não indisciplina, mas também sobre prejuízos que manifestações assim reconhecidas poderiam vir a causar ao adequado desenvolvimento das aulas, em outra questão apresentamos a mesma relação de situações anteriormente postas e solicitamos aos participantes que indicassem se seriam consideradas por eles como nada graves, pouco graves, graves ou muito graves.

Considerando os resultados anteriores bem como o fato de que professores de turmas do perfil inicial relatam maiores dificuldades com a indisciplina em sala de aula, não nos surpreendeu que, para os alunos concluintes, oito das 12 situações apresentadas tenham sido vistas como de maior gravidade do que na percepção dos alunos iniciantes. 
Outro dado significativo é que apenas o grupo dos professores não atribuiu qualquer gravidade a duas situações, que em outros tempos e contextos seriam consideradas como desrespeitosas: trocar bilhetinhos ou mensagens e interromper a fala do professor ou de algum colega com questionamento pertinente ao assunto. Em sentido diverso, não dar atenção ou ignorar o professor quando este se dirige à turma foi considerado como conduta grave pela maioria dos professores (83,3\%), mas nem tanto por seus alunos (49,1\% dos concluintes e $39,1 \%$ dos ingressantes).

Os dados em tela nos levam a refletir sobre a questão da autoridade pedagógica no ensino superior. Zuin (2015), Vasconcelos (2009) e Aquino (1996) estão entre os autores, que refletem sobre o tema da autoridade no exercício docente, o que fazem a partir de discussões que envolvem o direito ou poder de obedecer, tomar decisões, dar ordens em um contexto em que se deve adotar atitudes que levem o outro a crescer. Como ressalta Vasconcelos (1997), não existe uma autoridade em si, pois se trata de algo que se define em determinado contexto histórico, que se constrói no social e que deve, portanto, ser socialmente legitimado.

Tomando autores da escola de Frankfut como referência, Zuin (2015) inicia chamando a atenção para o entendimento horkheimiano de que "a autoridade valeria como uma relação em que alguém se submeteria racionalmente a outrem, em virtude de uma superioridade factual, e encerraria em si a tendência para superar a si própria" (HORKHEIMER, 1983, p. 102 apud ZUIN, 2015, p.755).

A escola é um importante espaço institucional, no qual o poder disciplinador se faz presente. Foucault nos apresenta, um conceito de governamentalidade, pois ligado à disciplina escolar permite entendê-la enquanto uma forma de governamento. Nesse sentido, podemos afirmar que a soberania, as disciplinas e a gestão governamental estão bem articuladas, uma vez que, Foucault entende como:

[...] conjunto constituído pelas instituições, procedimentos, análises e reflexões, os cálculos e as táticas que permitem exercer essa forma bem específica, ainda que complexa, de poder que tem por alvo principal a população, por forma maior de saber a economia política, por instrumento técnico essencial os dispositivos de segurança. (FOUCAULT, 2008, p. 111).

Assim posto, toda autoridade pedagógica dependeria de um elemento relacional, do estabelecimento de um vínculo respeitoso entre professores e alunos. Vínculo este que era mais fácil de ser obtido em épocas em que os alunos, mesmo que portadores de sentimentos ambivalentes em relação a seus mestres, ainda desejavam ser como seus professores, pois, nas palavras do autor, a imagem do professor ocupava um lugar importante no ideal de Eu do aluno (FOUCAULT, 2008).

Considerando o fato de que a nossa é uma sociedade imersa na cultura digital, a fragilização da autoridade pedagógica se manifesta, sobretudo, quando se coloca em discussão o uso de aparelhos celulares em sala de aula. Questionados a esse respeito, mais de $85 \%$ de todos os participantes associam à indisciplina a diversos usos não autorizados de equipamentos celulares, contudo, alguns usos são considerados como mais graves que outros. Para os professores, usar o equipamento para navegar na internet, sem que isso tenha sido solicitado ou autorizado é uma falta disciplinar bastante séria. Nenhum professor considerou a prática como pouco ou nada grave: metade 
dos docentes consideram-na grave e a outra metade muito grave. Os alunos, entretanto, têm outro entendimento, $28,3 \%$ dos concluintes e $40,7 \%$ dos ingressantes entendem que se trata de algo pouco ou nada grave.

Diferente da silenciosa navegação pela internet, permitir que o celular toque durante a aula é algo visto como mais grave pelos alunos concluintes $(49,1 \%)$ e pelos ingressantes $(35,6 \%)$ do que pelos professores $(33,3 \%)$. O dado sugere, mais uma vez, que os estudantes universitários abordados tendem a tratar como indisciplina, não necessariamente o que afronta normas ou autoridades institucionais, mas aquilo que pode atrapalhar seu aproveitamento ao tirar sua concentração.

\section{ENTRE O VIVIDO E O PERCEBIDO}

Compreendido o entendimento dos participantes sobre o que consideram como indisciplina no ensino superior, buscamos conhecer os desdobramentos de conflitos de ordem disciplinar ocorridos em sala de aula. Para isso, apresentamos aos participantes uma relação de situações solicitando a eles que identificassem se estas ocorreriam raramente, às vezes ou sempre: o professor chama a atenção ou da bronca na turma; o professor tenta negociar com a turma; o professor chama a atenção diretamente dos alunos envolvidos; o professor interrompe a aula e espera que a turma silencie; o professor altera o tom de voz ou dá tapas na mesa pedindo atenção; o professor interrompe a aula e se retira da sala; o professor pede aos alunos envolvidos que se retirem da sala; o professor anuncia ou chega a pedir a presença de um representante da coordenação do curso; os alunos envolvidos em indisciplina são acompanhados pela coordenação ou recebem alguma advertência.

Para a elaboração das assertivas foram consideradas as conclusões de Estrela (1994), que registra que as ações habituais no trato com a indisciplina vão desde ignorar o comportamento desviante até chamar a atenção, dirigir questionamentos aos alunos indisciplinados, fazer apelos à boa conduta, lembrar-se da regra que está sendo violada, retirar o estudante da sala de aula.

Os professores responderam em sua totalidade que sempre tentam negociar com a turma, e que raramente interrompem a aula, saem da sala ou pedem a presença de um representante da coordenação do curso. A maior parte dos docentes entendem que eles próprios sempre tentam resolver as situações, o que fazem, em sua maioria, chamando a atenção diretamente dos alunos envolvidos.

Mais de $75 \%$ dos docentes entendem, ainda, que raramente alteram a voz para pedir atenção, assim como raramente pedem aos alunos envolvidos que se retirem da sala. Sua postura em tais momentos é por eles vista como de autocontrole frente à turma.

Os estudantes, por sua vez, têm uma outra percepção um pouco diferente de como tais situações de conflitos são conduzidas em sala de aula. Dentre os concluintes, $32 \%$ entendem que às vezes, os professores alteram a voz e dão tapas na mesa em busca de atenção, e 21,6\% afirmam que de vez em quando, os envolvidos são convidados a se retirar da sala. Para este grupo de 
participantes, o que sempre acontece é o professor interromper a aula à espera de silêncio e, na sequência, chamar a atenção dos que estão diretamente envolvidos na situação.

Para os participantes dos três grupos, professores, alunos ingressantes e alunos concluintes, o que raramente acontece é os alunos envolvidos em indisciplina serem depois acompanhados pela coordenação ou mesmo receberem alguma advertência. A este respeito cabe observar que no estatuto da IES investigada (2017, p. 50), em seu artigo 191, é previsto que a pena de advertência é aplicável por "desrespeito a qualquer membro da comunidade acadêmica, por perturbação da ordem no recinto do Centro Universitário", enquanto o artigo 193 estabelece que a pena de suspensão de até $15 \%$ dos dias letivos é aplicável mediante:

agressão a outro aluno, ofensa a qualquer membro dos corpos docente [...], improbidade na execução dos trabalhos escolares, ofensa moral a qualquer autoridade da administração superior, impedimento do exercício das funções pedagógicas, científicas ou administrativas. (idem, p. 50).

A pena de desligamento é aplicável pela "reincidência nas infrações, agressão a qualquer membro do corpo docente ou técnico-administrativo e por atos incompatíveis com a dignidade da vida escolar" (ibidem).

Diante dos estudos de Rebelo (2002), Aquino (1996) e Oliveira (2005), não se pode mais encarar a disciplina como manutenção da ordem e obediência das regras pré-estabelecidas, por meio de ameaças de punição, mas sim, como uma construção que se dá através de compromissos, acordos firmados entre ambas as partes, aluno e professor. Neste caso, acredita-se que pode haver colaboração entre professor e aluno para que, a sala de aula seja um lugar de encontro de saberes ao mesmo tempo de construção do conhecimento numa relação de respeito entre as partes.

Depois de conhecer os participantes percebem como conduta indisciplinada no ensino superior, a que gravidade, atribuem a tais comportamentos e como, segundo sua percepção, os professores e a IES lidam com essas situações quando acontecem em sala de aula, se busca o entendimento dos sujeitos acerca das motivações e responsabilidades pela indisciplina.

Inicia-se procurando verificar o que os participantes trazem consigo, representações estereotipadas acerca do aluno indisciplinado e do professor em cuja aula a indisciplina se manifesta. Para tal, apresentamos um grupo de assertivas nas quais crenças sociais e estereótipos circulantes foram misturados a elementos encontrados pontualmente nas conclusões de trabalhos científicos sobre indisciplina escolar: alunos tendem a ser mais indisciplinados que alunas; a indisciplina ocorre mais em aulas de docentes mais jovens; a indisciplina ocorre mais em aulas regidas por mulheres; a indisciplina ocorre mais nas aulas dos professores menos experientes; a indisciplina ocorre mais em componentes curriculares considerados pelos alunos como secundários; alunos que têm religião tendem a ser menos indisciplinados; alunos muito indisciplinados geralmente têm problemas psicológicos elou neurológicos; a indisciplina é sobretudo uma questão cultural. Aos participantes foi solicitado que identificassem se concordam, discordam ou concordam parcialmente do conteúdo de cada frase. 
Diferente do que tem sido constatado em estudos sobre a indisciplina no ensino fundamental, os participantes da pesquisa discordaram do entendimento de que a indisciplina tenha relações com gênero. Frente à afirmação de que a indisciplina ocorre mais em aulas regidas por mulheres, 83,3\% dos professores, $84,8 \%$ dos alunos iniciantes e $68 \%$ dos alunos concluintes, discordaram, assim como $66,7 \%$ dos docentes e $74 \%$ dos universitários concluintes discordaram também da afirmação de que os alunos são mais tendentes ao comportamento indisciplinado do que as alunas.

Os dados apontam para o que foi afirmado por Vasconcellos (2000, p. 56), que defende que a questão disciplinar

se expandiu em termos de gêneros: antes, era um problema praticamente só dos meninos; no presente, as meninas não deixam por menos. $E$ de faixas etárias: houve época em que a reclamação vinha dos professores do final do ensino fundamental; atualmente, tem vindo até da educação infantil e, no polo oposto, do ensino superior.

Cumpre registrar, entretanto, a presença de estudos que vão em sentido contrário. Em sua pesquisa Reis (2011, p.96), observa que as normas e discursos de gênero reproduzidos na educação escolar reservam às meninas "a docilidade, a responsabilidade, o interesse, a disciplina, a organização" enquanto aos meninos ficam reservados "a agitação, a ousadia, o brincar e falar muito, a insubmissão, o desinteresse e a indisciplina".

Diferente do que ocorre em relação à temática gênero, professores e alunos não pensam de forma similar em relação à crença circulante, segundo à qual alunos muito indisciplinados geralmente têm problemas psicológicos e/ou neurológicos. Enquanto apenas $25 \%$ dos docentes discordam dessa assertiva, o número dos discordantes entre os alunos é bem maior: $72,8 \%$ dos ingressantes e $55,1 \%$ dos concluintes.

Oliveira (2005) observa que, a questão da indisciplina também pode ter origem advinda de fatores psicológicos ou emocionais, que acarretam a falta de atenção e a falta de concentração durante a aula. Além dos já banalizados distúrbios de déficit de atenção e hiperatividade, outras manifestações da mesma ordem podem interferir na capacidade de atenção e de concentração do aluno e influenciar comportamentos considerados como indisciplinados.

Não obstante, importa lembrar a crítica colocada por Aquino (1996) quanto às interpretações "psicologizantes" da indisciplina, segundo as quais esta é tratada como "indício de uma carência estrutural que se alojaria na interioridade psíquica do aluno, determinada pelas transformações institucionais na família e desembocando nas relações escolares" (idem, p. 48).

A carência de atenção e de afeto pode manifestar-se na forma de comportamentos indisciplinados na universidade ou ainda, desrespeito e falta de limites. Tais comportamentos podem ser tentativas para chamar a atenção dos colegas e, principalmente, dos professores (AQUINO, 1996; OLIVEIRA, 2005), contudo, um fenômeno com essa complexidade não pode ser analisado de forma tão linear. 
Ainda para Aquino (1996, p. 96) "ninguém nasce rebelde ou disciplinado, já que essas características não são inatas, nem todo adolescente será necessariamente indisciplinado". Assim, o comportamento indisciplinado ou disciplinado não surge de fatores isolados, como por exemplo, unicamente da educação familiar, da falta de autoridade do professor, dentre outros, mas da multiplicidade de influências que interferem sobre o indivíduo ao longo de seu desenvolvimento. Se leituras baseadas numa psicologia genérica ainda tendem a reduzir a questão da indisciplina a resultado de atributos psicológicos individuais, tal como observado pelo autor em sua crítica, a adesão a esta perspectiva não foi verificada no universo estudado.

Para $38 \%$ dos discentes iniciantes, $50 \%$ dos concluintes e $58,3 \%$ dos docentes, concordam que a indisciplina ocorre mais nas aulas dos professores menos experientes, pois na visão de Gaeta e Masetto $(2013$, p.10) "é natural que os professores iniciantes na docência do ensino superior [...], apresentam uma série de dúvidas, expectativas e ansiedades, tantas as relacionadas ao domínio do conteúdo específico da sua disciplina" [...]. O início de carreira ou a pouca experiência representa, portanto, uma fase crítica em relação às experiências anteriores e os ajustes a serem feitos, em função do trabalho e do confronto inicial, com a complexa realidade do exercício da profissão docente.

O tempo de experiência, o tipo de formação dos professores, a realidade socioeconômica e cultural dos alunos são alguns dos cenários que compõem o cotidiano das salas de aula. Acredita-se que, é com o passar do tempo que grande parcela dos professores iniciantes desenvolve maior segurança, experiência, domínio do conteúdo, engajamento com a organização curricular e adquire a identidade docente. É fundamental que o professor tenha uma clara compreensão de como esse conhecimento deve ser trabalhado, a fim de que seja significativo, útil e acessível para os alunos.

A docência na universidade, segundo Pimenta e Anastasiou (2005), configura-se como um processo contínuo de construção de identidade docente e tem por base os saberes da experiência construídos no exercício profissional, mediante o ensino dos saberes das áreas de conhecimento.

Quanto às relações geracionais e ao tempo de docência, $58 \%$ dos professores discordam que a indisciplina ocorra mais em aulas ministradas por docentes mais jovens.

A maioria dos professores $(58,3 \%)$ concordam ainda que, a indisciplina ocorre mais em componentes curriculares considerados pelos alunos como secundários. D’Antola (1989, p. 37) diz que "a disciplina só é eficaz quando tem uma meta a atingir, o conhecimento exige disciplina e qualquer saber instiga a disciplina a ser mais rigorosa para poder apreender todas as diferentes nuances". A rotina e a mecanização da exposição dos conteúdos secundários durante as aulas, podem causar o desinteresse e consequentemente gerar a indisciplina, causando também o insucesso na aprendizagem.

Ao identificar mecanismos de poder na sociedade, Foucault caracteriza o poder disciplinar como autor dos acontecimentos decorrentes de uma atitude padronizada dos homens na modernidade. Segundo ele, vivemos na época dos corpos disciplinados, em que a disciplina produz, para a modelagem e controle dos corpos, ferramentas que vão nortear o processo de construção do poder e normatização das condutas, adotando caracteres para sua aquisição. "O poder que se exerce como 
condução de condutas, é a ação de conduzir os outros, ou seja: é a maneira de se comportar num campo amplo de possibilidades". Afinal, "o exercício do poder consiste em conduzir condutas e em ordenar a probabilidade" (FOUCAULT, 1995, p. 243-244).

A indisciplina no contexto do ensino superior parece ser o primeiro sintoma de que algo está errado no processo ensino aprendizagem. Pires (1999, p. 184) ressalta que [...] "o ideal para o efetivo processo de ensino aprendizagem é o professor alcançar uma disciplina consciente e interativa, marcada por participação, respeito, responsabilidade, construção do conhecimento, formação do caráter e da cidadania do aluno".

A maioria dos participantes (alunos iniciantes $62 \%$, concluintes $59,2 \%$ e professores $66,6 \%$ ) concorda que, os alunos que receberam boa educação familiar tendem a ser menos indisciplinados. Embasado nos estudos de Oliveira (2005, p. 38) ela afirma que "na maioria das vezes as atitudes de indisciplina são reflexos de uma educação recebida não apenas pela sociedade, mas no ambiente familiar".

\section{CONSIDERAÇÕES FINAIS}

A questão da indisciplina tem ocupado um espaço cada vez maior no cotidiano educacional e vem se tornando, um desafio para professores e gestores que nem sempre sabem o que fazer para impedir ou minimizar estes conflitos presentes desde a educação infantil até o nível superior, nas instituições de ensino públicas ou privadas, e que se manifestam nas relações dos alunos entre si, dos alunos com os professores (AQUINO, 1996; VASCONCELLOS, 2015).

Ao abordar professores e alunos de um curso da área de saúde animal, constatamos que as concepções dos participantes acerca do que seja, ou não indisciplina, remetem às apresentadas em Estrela (1994) e Aquino (1996), quando os autores relacionam a indisciplina a comportamentos que se contrapõem às normas que foram estabelecidas, com o fito de garantir o bom andamento das atividades escolares.

Compreendemos, ainda, que o padrão aceito de comportamento escolar disciplinado, dentro da sociedade ocidental, foi forjado também historicamente, entre os séculos XVIII e XIX, conforme observou Michel Foucault (1999). Através de intrincados mecanismos de vigilância e punição, a sociedade industrial burguesa docilizou os corpos, disciplinarizando alunos, detentos, operários, mulheres, loucos. Entretanto, a despeito da rígida disciplina, herdeira do século XIX, os corpos igualmente se rebelam.

Ainda que os três grupos de sujeitos identifiquem como indisciplina as mesmas situações, a pesquisa revelou que o valor por eles atribuído aos eventos disruptivos é um tanto diferente. Os estudantes que se encontram na transição do ensino médio para o ensino superior são os que atribuem menor gravidade à ocorrência de situações de indisciplina em sala de aula, diferentemente 
dos concluintes, que se incomodam com tais situações sempre que estas atrapalham o andamento das aulas e se tornam ameaças ou obstáculos ao melhor desempenho acadêmico.

Consideramos que, diante de um mundo marcado pela tecnologia, em que o acesso à informação está, literalmente, ao alcance das mãos, os sujeitos envolvidos parecem não responder com efetividade às urgências do novo tempo. Como o acesso à web se dá, via de regra, através dos celulares, o comportamento de navegar na internet durante a aula, entendido como expressão de indisciplina por todos os participantes, é, ao mesmo tempo, uma realidade no ensino superior e fora dele.

Os mesmos estudantes que entendem ser o acesso ao celular uma forma de indisciplina e que, em questão aberta, sugerem sua proibição por parte da instituição, também reclamam por aulas mais dinâmicas, mais atrativas, com maior envolvimento dos alunos, opinando que esta seria uma forma de enfrentamento do desinteresse por eles identificado, como uma das principais motivações para a ocorrência de situações de indisciplina.

As duas sugestões - interdição ao uso do celular e aulas mais dinâmicas e participativas - nos oferecem elementos para se pensar. Em primeiro lugar, cabe redimensionarmos a noção que ainda possuímos de indisciplina escolar. Descontando atitudes de violência e desacato deliberado (que, aliás, não apareceram na pesquisa), o que mais habitualmente é considerado como indisciplina diz respeito, sobretudo, a desinteresse pela aula e/ou desatenção ao docente. Na sociedade do espetáculo está posta uma expectativa de que, as aulas também se tornem antes eventos lúdicos do que encontros de produção de conhecimento.

Em conclusão, entendemos que, ao mesmo em que o trabalho com o ensino superior nos exige um redimensionamento da noção de indisciplina escolar, em uma sociedade imersa na cultura digital e tão marcada pela desvalorização do trabalho docente, o lugar ocupado pelo professor no imaginário social também deve ser levado em consideração, sendo este, portanto, tema para novas pesquisas.

\section{REFERÊNCIAS}

1. AQUINO, J. G (Org.). Indisciplina na escola: alternativas teóricas e práticas. 8. ed. São Paulo: Summus, 1996. Indisciplina: o contraponto das escolas democráticas. São Paulo: Moderna, 2003.

Docência, Poder e Liberdade: dos processos de governamentalização à potência de existir nas escolas. 2009. 216 f. Tese de Livre Docência. Departamento de Filosofia da Educação e Ciências da Educação. Universidade de São Paulo, 2009. Disponível em: < http://www.teses.usp.br/teses/disponiveis/livredocencia/48/tde-19032013-093316/pt-br.php>. Acesso em: 17 jul. 2017. 
4. Pesquisa, São Paulo, v. 46, n. 161, p. 664-692, set. 2016. Disponível em <http://www.scielo.br/scielo.php?script=sci_arttext\&pid=S010015742016000300664\&lng=en\&nrm =iso>. Acesso em 18 de set. 2017.

5. AQUINO, J. G.; RIBEIRO, C. Processo de governamentalização e a atualidade educativa: a liberdade como eixo problematizador. Educação e Realidade, Porto Alegre, v. 34, n. 2, p. 58-71, maio/ago. $2009 . \quad$ Disponível em: <http://seer.ufrgs.br/educacaoerealidade/article/download/8202/5530>. Acesso em: 17 jul. 2017.

6. ARAÚJO, U. F. de. Moralidade e indisciplina: uma leitura possível a partir do referencial piagetiano. In: AQUINO, J. G. (Org.). Indisciplina na escola: alternativas teóricas e práticas. 8. ed. São Paulo: Summus, 1996.

7. CHIZZOTTI, A. Pesquisa em ciências humanas e sociais. 3. ed. São Paulo: Cortez, 1998.

8. D'ANTOLA, A. (Org.). Disciplina na escola: autoridade versus autoritarismo. São Paulo: EPU. 1989.

9. DEBARBIEUX, E. La Violence en milieu scolaire (vol. 2 - Le désordre des choses). Paris: ESF, 1999.

11. ESTRELA, M. T. Relação pedagógica, disciplina e indisciplina na aula. Portugal: Porto, 1994.

12. FOUCAULT, M. A hermenêutica do sujeito. São Paulo: Martins Fontes, 2004a. A ética do cuidado de si como prática da liberdade. In: MOTA, M. B. (Org.). Ditos e escritos. Rio de Janeiro: Forense Universitária, 2004b. p. 264-287.

GAETA, C.; MASETTO, M. T. O professor iniciante no ensino superior: aprender, atuar e inovar. São Paulo: Senac, São Paulo, 2013. 
18. IES. Instituição de Ensino Superior. Projeto Pedagógico do Curso de Medicina Veterinária. Patos de Minas, 2016. 503p.

Estatuto da IES. Aprovado pela Res. CON/IES n409, de 30 de dezembro de 2013. Alterado pela Res. CON/IES n424, de 16 de junho de 2014. Alterado pela Res. CON/IES n434, de 11 de maio de 2015. Alterado pela Portaria Reitoria $n^{\circ} 2051$, de 20 de maio de 2016, referendada pela Res. CON/IES $n^{\circ} 453$, de 20 de dezembro de 2016. Alterado pela Res. CON/IES n²463, de 03 de maio de 2017. Patos de Minas/MG, 2017. 55 p.

MÁRQUES, F. T.; SOUSA, A. R. Poder e Violência nas relações escolares: uma abordagem foucaultiana. Revista Querubim, ano 12, n. 28, vol. 01, p 116-123, fev. 2016. Disponível em: $<$ http://www.uff.br/feuffrevistaquerubim/images/arquivos/zquerubim_28_v_1.pdf>. Acesso em: 30 mar. 2017.

21. MÁRQUES, F. T. Violência e normalização na escola: a produção da diferença como condição patológica. Relatório (Pós-doutorado em Estudos Culturais). 2015. Programa Avançado de Cultura Contemporânea, Universidade Federal do Rio de Janeiro - UFRJ, 2015.

OLIVEIRA, M. I. A indisciplina escolar: determinações, consequências e ações. Brasília: Líber Livro, 2005.

PIMENTA, S. G.; ANASTASIOU, L. G. C. Docência no ensino superior. São Paulo: Cortez, 2005.

PIRES, D. B. Disciplina: construção da disciplina consciente e interativa em sala de aula e na escolar. Educação e Sociedade, ano XX, n. 66, p. 181-185, abr. 1999. Disponível em: <http://www.scielo.br/scielo.php?script=sci_arttext\&pid=S0101-73301999000100009>. Acesso em 12 out. 2016.

PORTOCARRERO, V. Instituição Escolar e Normalização em Foucault e Canguilhem. Educação \& Realidade, v. 29, $\quad$ n. 1, pp. 169-185, 2004 Disponível em: <http://seer.ufrgs.br/index.php/educacaoerealidade/article/view/25424>. Acesso em 16 jan. 2015.

REBELO, R. A.A. Indisciplina escolar: causas e sujeitos. 3.ed. Rio de Janeiro: Vozes, 2002.

REIS, C. D. Currículo escolar e gênero: a constituição generificada de corpos e posições de sujeito meninos-aluno. 2011. 154 f. Dissertação (Mestrado em Educação) - Universidade Federal de Minas Gerais - UFMG, Belo Horizonte, 2011. Disponível em: < https://www.scribd.com/document/.../Dissertacao-Curriculo-Escolar-e-Genero >. Acesso em: 15 nov. 2017. 
28. VASCONCELLOS, C. S. Disciplina: construção da disciplina consciente e interativa em sala de aula e na escola. 11. ed. São Paulo: Libertad, 2000. Indisciplina e disciplina escolar: fundamentos para o trabalho docente. São Paulo: Cortez, 2009.

30. VEIGA-NETO, A. Cultura, culturas e educação. Revista Brasileira de Educação, n.23, p. 5-15, maio/jun/jul/ago. 2003. Disponível em: < http://www.scielo.br/pdf/rbedu/n23/n23a01.pdf>. Acesso em: 10 jun. 2016.

31. ZUIN, C. A. S. A autoridade pedagógica em tempos de cultura digital. Educação e Filosofia, v. 29, n. $58, \quad$ p. $745 \quad$ - 769 , jul./dez. 2015. Disponível em: <http://www.seer.ufu.br/index.php/EducacaoFilosofia/article/view/26187>. Acesso em: $21 \mathrm{fev}$. 2018.

\section{Aparecida Silvério Rosa}

Mestre em educação pela Universidade de Uberaba (UNIUBE). Professora do Centro Universitário de Patos de Minas - UNIPAM.

\section{Fernanda Telles Márques}

Doutora em Sociologia pela UNESP de Araraquara, com pós-doutorado em Estudos Culturais pela UFRJ. Professora no Programa de Pós-Graduação em Educação da Universidade de Uberaba UNIUBE, Uberaba, Brasil.

\section{Como citar este documento:}

ROSA, Aparecida Silvério; MÁRQUES, Fernanda Telles. Indisciplina no ensino superior: perspectivas docentes e discentes. Reflexão e Ação, Santa Cruz do Sul, v. 27, n. 1, dez. 2018. ISSN 1982-9949. Disponível em: <https://online.unisc.br/seer/index.php/reflex/article/view/12100>. Acesso em: . doi:https://doi.org/10.17058/rea.v27i1.12100. 